\title{
Wedge Filter Device
}

National Cancer Institute

\section{Source}

National Cancer Institute. Wedge Filter Device. NCI Thesaurus. Code C50361.

A filter designed so that its thickness or transmission properties increase from one edge to another. 